\title{
Geomorphologic patterns of dune networks in the Tengger Desert, China
}

\author{
WEN Qing ${ }^{1}$, DONG Zhibao ${ }^{1,2 *}$ \\ ${ }^{1}$ Cold and Arid Regions Environmental and Engineering Research Institute, Chinese Academy of Sciences, Lanzhou 730000, \\ China; \\ ${ }^{2}$ Department of Geography, Shaanxi Normal University, Xi'an 710062, China
}

\begin{abstract}
Dune networks are widely distributed in the world's deserts, which include primary ridges and secondary ridges. However, they have not been sufficiently studied in a systematic manner and their origins and spatial and morphological characteristics remain unclear. To provide information on the geomorphology of dune networks, we analyze the software geomorphologic patterns of the dune networks in China's Tengger Desert using matrix and laboratory to process remote-sensing images. Based on analysis of image features and their layout in a topographic map, we identify two types of dune networks (square and rectangular dune networks) with different size and morphological structures in the Tengger Desert. Four important geomorphic pattern parameters, ridge length, spacing, orientation and defect density, are analyzed. The length of primary ridges of dune networks decreases from northwest of the desert to the southeast, resulting an increasing spacing and a transition from rectangular dune networks to square dune networks. Wind regime and sediment supply are responsible for the variation in pattern parameters. We use the spacing and defect density data to estimate the construction time of dune networks and found that the dune networks in the Tengger Desert formed since about 1.3 ka BP.
\end{abstract}

Keywords: aeolian geomorphology; dune networks; geomorphological parameters; geomorphic pattern analysis; Tengger Desert

Citation: WEN Qing, DONG Zhibao. 2016. Geomorphologic patterns of dune networks in the Tengger Desert, China. Journal of Arid Land, 8(5): 660-669. doi: 10.1007/s40333-016-0092-x

Dune networks are widely distributed in the world's deserts, which include primary ridges and secondary ridges, and are formed in two wind directions that are almost perpendicular (Hasi et al., 1999). They comprise intercrossing groups of dune ridges and form a reticulate shape. Dune networks generally appear in areas with abundant sand supply or aeolian sand or dense groups of dunes (Breed et al., 1979; Wasson and Hyde, 1983a, b; Warren and Kay, 1987; Pye and Tsoar, 1990; Cooke et al., 1993; Livingstone and Warren, 1996). Previous studies described the shapes and distributions of dune networks in different regions of the world, such as the Namib Desert (Lancaster, 1989), the Kalahari Desert (Bullard, 1997), coastal dune fields in South Africa (Illenberger, 1988), the Sahara Desert (Monod, 1958; Wilson, 1972; Cooke and Warren, 1973), the central desert of Australia (Brookfield, 1970; Mabbut, 1977), the deserts of Oman and Iraq in the Arabian Peninsula (Warren and Kay, 1987; Warren, 1988), the Tengger Desert (Chen, 1965; Yang et al., 1994), Hobq Desert and Ulan Buh Desert in China (Zhu et al., 1980; Wu, 1987; Zhong, 1999).

Researchers have attempted to understand the formation of dune networks primarily based on

*Corresponding author: DONG Zhibao (E-mail: zbdong@1zb.ac.cn)
Received 2016-02-04; revised 2016-04-06; accepted 2016-04-09
C Xinjiang Institute of Ecology and Geography, Chinese Academy of Sciences, Science Press and Springer-Verlag Berlin Heidelberg 2016 
morphological and wind regime analysis. Analyzing shapes and regional wind conditions, Chen (1965) proposed that dune networks were formed under the influence of interactions of two nearly perpendicular winds, with the prevailing wind creating the primary ridges and the subordinate wind creating the secondary ridges. Warren and Kay (1987) and Warren (1988) measured the dune shapes and networks in Oman, and found that the dune networks were formed by winds with different directions. Ling et al. (1988) monitored the dynamic processes of the dune networks in the Tengger Desert. According to Yang et al. (1994), a dune network was formed as both wings of a barchan dune advanced rapidly and connected with the next barchan dune. The ridges of the barchan dunes subsequently formed the main ridges in the dune networks and the connected wings of the barchan dunes formed the secondary ridges. Liu (1995) proposed that a dune network was formed under the joint actions of winds in three distinct wind directions. Previous studies analyzed the surface air current, sediment grain size distribution, sedimentary structure and other factors in describing the dune networks on the southeastern edge of the Tengger Desert (Hasi, 1995, 1998; Hasi and Wang, 1996; Hasi et al., 1999). Zhang et al. (2015a) combined wind regime data from automated weather stations in the western and southwestern Tengger Desert with remote-sensing data to define the relationship between the wind energy environment and aeolian geomorphology. Zhang et al. (2015b) analyzed the grain size parameters of surface sediment.

Dune networks have been studied less than other types of dunes, and there has been no systematic research on their morphological features. Geomorphic patterns are important and obvious features of dune landforms and therefore attracted the attention of early desert researchers. The term "geomorphic pattern" refers to the spatial structure of dune arrangement, which can be characterized by several parameters. The first research on this topic was conducted by Hallet (1990), who revealed some of the true complexity of dune landforms: even a seemingly simple dune may be part of a more complicated geomorphic pattern and this increases the difficulty of dune landform research. The objective of this study was to analyze the geomorphic pattern parameters of dune networks in China's Tengger Desert using geomorphic pattern analysis to compare the morphology and wind environment between two types of dune networks and to estimate the construction time of dune networks.

\section{Study area}

The Tengger Desert lies between $37^{\circ} 20^{\prime}-40^{\circ} 10^{\prime} \mathrm{N}$ and $102^{\circ} 30^{\prime}-05^{\circ} 55^{\prime} \mathrm{E}$ (Fig. 1) in the

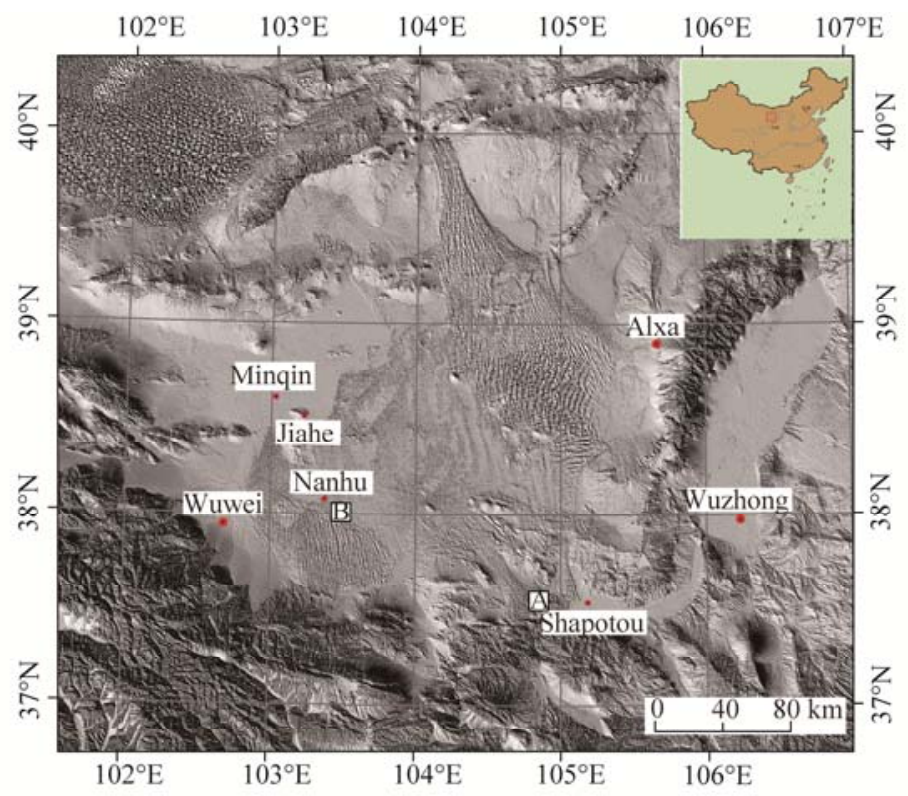

Fig. 1 The location of the sampling areas: square dune networks (A) and rectangular dune networks (B) 
southeastern Alxa Plateau, bordered to the southwest by the Qilian Mountains, to the east and northwest, by the Helan Mountains and Badain Jaran Desert, respectively. The Tengger Desert covers an area of about $47,350 \mathrm{~km}^{2}$ and is the third largest shifting sand sea in China. Climatically, the Tengger Desert is situated at the convergence of the arid and semi-arid steppe. The climate is temperate, dry and windy. The annual mean temperature is $7.0^{\circ} \mathrm{C}-9.7^{\circ} \mathrm{C}$, with monthly means ranging from $-6.7^{\circ} \mathrm{C}$ in January to $24.1^{\circ} \mathrm{C}$ in July. The area receives an average precipitation of 100-200 mm annually, gradually decreasing from southeast to northwest. There are dozens of dune areas in the desert and dune networks cover $17,950 \mathrm{~km}^{2}$ (38\% of the desert).

In the Tengger Desert, dune networks consist of the SW-NE oriented primary ridges and SE-NW oriented secondary ridges (almost perpendicular to primary ridges). Based on an examination of image features and dune locations in a topographic map (1:400,000 geomorphologic map of the Tengger Desert), we identify two types of dune networks that differed in size and morphological structures. We divide them into square dune networks and rectangular dune networks. Square dune networks have primary and secondary ridges that are roughly the same length, whereas the length of primary ridges of rectangular dune networks are longer than the that of secondary ridges (Fig. 2).

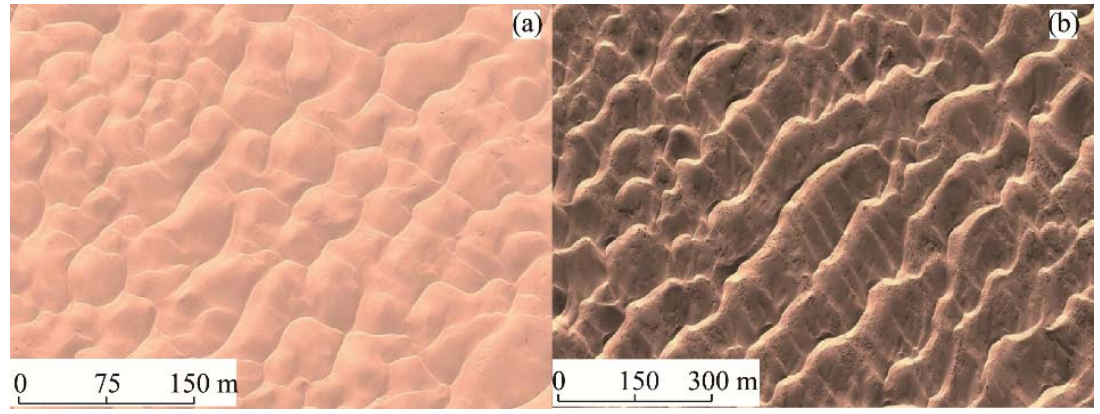

Fig. 2 Typical dune networks in the Tengger Desert: (a) square dune networks (site A in Fig. 1) and (b) rectangular dune networks (site B in Fig. 1)

\section{Methods}

Our analysis of the geomorphologic patterns of the dune networks in the Tengger Desert is based on Google Earth high-resolution images available online. We use the matrix and laboratory (MATLAB) software (www.mathworks.com) to process the remote-sensing image data. Specifically, we use differences in the grayscale values for windward and leeward slopes of the dunes (Fig. 3) to extract the dune ridges in the dune networks (Jiang et al., 2013). Visual inspection shows that MATLAB generally does an excellent job for identifying dune ridges. We examine the images by the MATLAB software to measure the geomorphologic parameters of the ridge length, the space between dune ridges and the orientation of the ridges. We also calculate the defect density following the method proposed by Werner and Kocurek (1999). Defect dynamics suggests that the changes in parameters of dune geomorphic patterns result from changes in the defect characteristics and can be used to determine dune construction time (Werner and Kocurek, 1999). According to Werner and Kocurek (1999), aeolian bedforms are represented by their crest lines, which are interrupted by $N$, the randomly distributed pairs of defects. The defect density is defined as the number of pairs of defects per unit of dune crest length. The defect density equals as $\rho=N / L$, where $N$ is the number of pairs of defects, $L$ is the dune crest length.

Figure 3 shows an example of the sequence extracted from the image of a typical dune field. Dune height in the Tengger Desert are relatively low and the height ranging from 5 to $20 \mathrm{~m}$ account for $60 \%$. To determine the magnitude of the spatial variation in the pattern parameters, we divide the study region into $2 \mathrm{~km} \times 2 \mathrm{~km}$ cells. We randomly select 100 cells from each of the two types of dune networks for analysis. We use MATLAB Platform to calculate the parameters of the primary ridges of the dune networks from remote images and measure the parameters of the 
secondary ridges of the dune networks by hand. Table 1 summarizes the ridge length, spacing and orientation (strike) in the two sample regions.

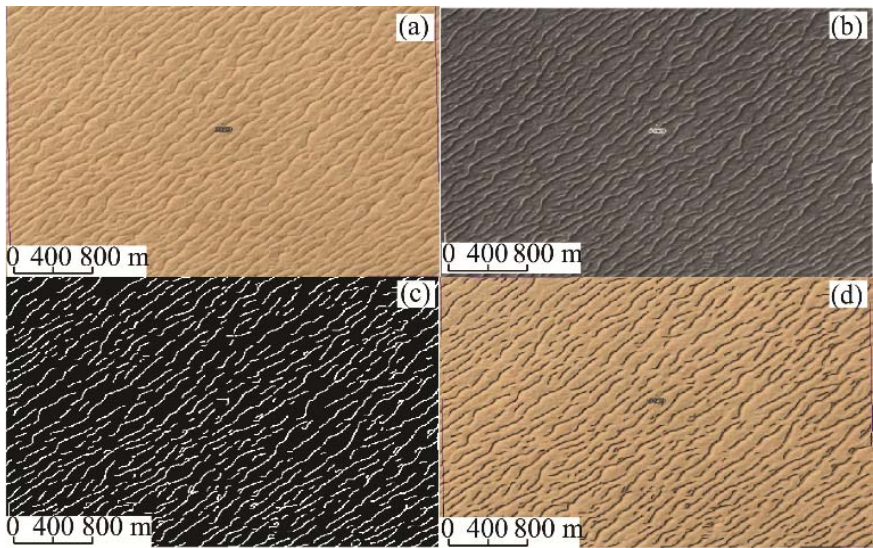

Fig. 3 The primary ridges extracted from remote-sensing images using the MATLAB software: image of (a); pre-processed greyscale image of the lattice structure (b); image of the extracted sand ridges (c); image imported from Google Earth (d). a-d are at the same location $\left(37^{\circ} 56^{\prime} 40.23^{\prime \prime} \mathrm{N}, 103^{\circ} 32^{\prime} 57.75^{\prime \prime} \mathrm{E}\right)$.

Table 1 Summary of the dune primary ridge length, spacing and orientation in the two sample areas of dune networks as shown in Fig. 1

\begin{tabular}{|c|c|c|c|}
\hline & & Site A & Site B \\
\hline $\begin{array}{l}\text { Geomorphologic } \\
\text { features }\end{array}$ & & $\begin{array}{l}\text { Mostly square dune networks (Fig. 2a). The } \\
\text { spacing between the main ridges is similar to } \\
\text { that between the secondary ridges. Square } \\
\text { dune networks have been developed where } \\
\text { the terrain rises and falls slightly. Barchan } \\
\text { chains are common in low-lying areas. }\end{array}$ & $\begin{array}{l}\text { Mostly rectangular dune networks (Fig. 2b). } \\
\text { The spacing between the main ridges differs } \\
\text { from that between the secondary ridges. } \\
\text { Rectangular dune networks have mainly } \\
\text { been developed in open areas where the } \\
\text { terrain is relatively flat, especially in the } \\
\text { southern Tengger Desert. }\end{array}$ \\
\hline \multirow{2}{*}{ Ridge length (m) } & Average & 85.1 & 115.6 \\
\hline & Range & $57.6-104.7$ & $70.1-206.6$ \\
\hline \multirow{2}{*}{ Spacing $(\mathrm{m})$} & Average & 100.8 & 77.9 \\
\hline & Range & $71.9-164.9$ & $54.5-119.9$ \\
\hline \multirow{2}{*}{$\begin{array}{l}\text { Strike of the } \\
\text { primary ridge }\left({ }^{\circ}\right)\end{array}$} & Average & 56.0 & 46.0 \\
\hline & Range & $49.0-67.0$ & $37.0-61.0$ \\
\hline \multirow{2}{*}{ Height (m) } & Average & 8.0 & 9.2 \\
\hline & Range & $3.7-18.4$ & $6.9-10.7$ \\
\hline
\end{tabular}

\section{Results and discussion}

\subsection{Ridge length and spacing}

We select 100 sample cells from each of the two types of dune networks. Figure 4 shows the cumulative probability for dune ridge length. The average ridge length of the square dune networks is about $85 \mathrm{~m}$. The length of the primary dune ridge of the square dune networks consists of two parts (Figs. 2a and 4a) and can be divided into two groups by an inflection point. The length of primary ridges in the first group is less than $80 \mathrm{~m}$ and this group accounts for $30 \%$ of the dunes; the length in the second group is between 80 and $100 \mathrm{~m}$, and this group accounts for $70 \%$ of the dunes. The average length of the primary ridges of the rectangular dune networks is about $116 \mathrm{~m}$ (Fig. 2b). The length of the primary ridges also consists of two parts divided by an inflection point. The length of primary ridges in the first group is less than $100 \mathrm{~m}$ and this group accounts for $40 \%$ of the dunes. The second group is between 100 and $200 \mathrm{~m}$, and this group 
accounts for $60 \%$ of the dunes. The length of the primary ridges generally decreases from the northwest to the southeast (i.e. from the rectangular dune networks at site $\mathrm{B}$ to the square dune networks at site $\mathrm{A}$ ).

Figure $4 \mathrm{~b}$ shows the cumulative probability distribution for the ridge length of the secondary ridges of the dune networks. The length of the secondary ridges increases from the northwest to the southeast (i.e. from the rectangular dune networks at site B to the square dune networks at site A). It is implied that the transition from rectangular dune networks to square dune networks from the northwest of the desert to the southeast is a result of decreasing primary ridges and increasing secondary ridges.
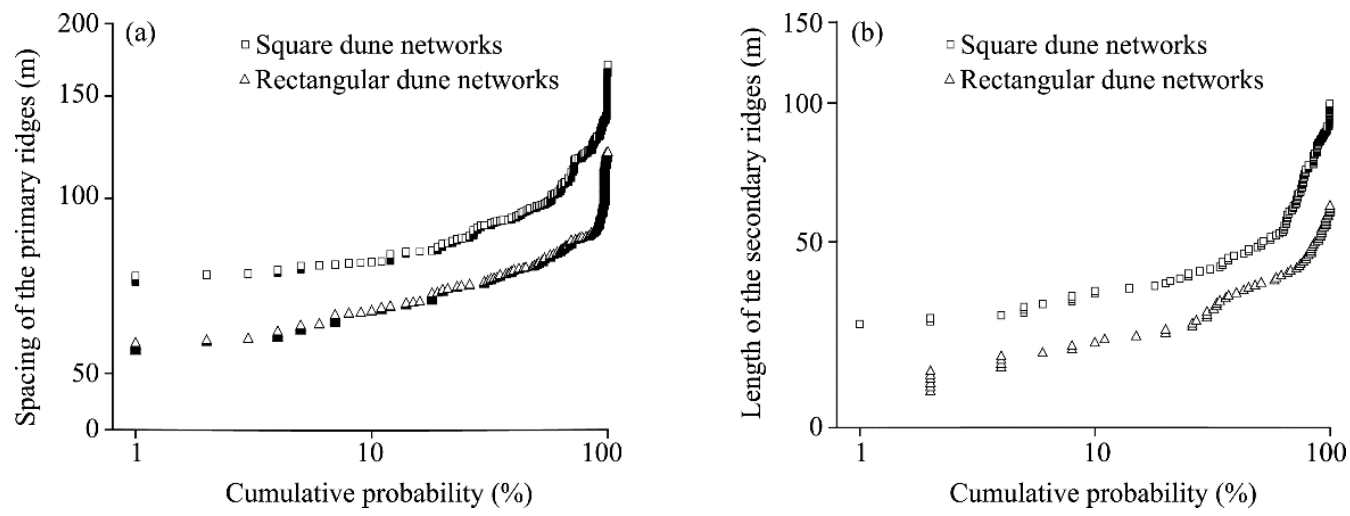

Fig. 4 Cumulative probability distributions of ridge length for primary dune ridges (a) and secondary dune ridges (b)

Spacing between dune ridges is one of the most important geomorphologic pattern parameters. Werner and Kocurek (1999) believed that dune ridge spacing was a function of time, initial conditions and the behavior of defects under which a dune formed and changed during the dune's subsequent development. In the Tengger Desert, the average spacing between the primary ridges of square and rectangular dune networks is 101 and $78 \mathrm{~m}$, respectively. The cumulative probability distribution (Fig. 5) is a continuous smooth curve. The regions with low spacing occur with longer ridge length; and high spacing occur with shorter ridge length (Fig. 5a). The average spacing of rectangular dune networks is shorter than that of the square dune networks.

For the secondary ridges, the change of the spacing is similar to the primary ridges (Fig. 5b). The average ridge spacing is shorter for the rectangular dune networks, and the spacing of the secondary ridges increases from northwest to southeast. It can be understood that the increase in spacing, increase in length of the secondary ridges and the transition from rectangular dune networks in the northwest of the desert to square dune networks in the southeast are similar.
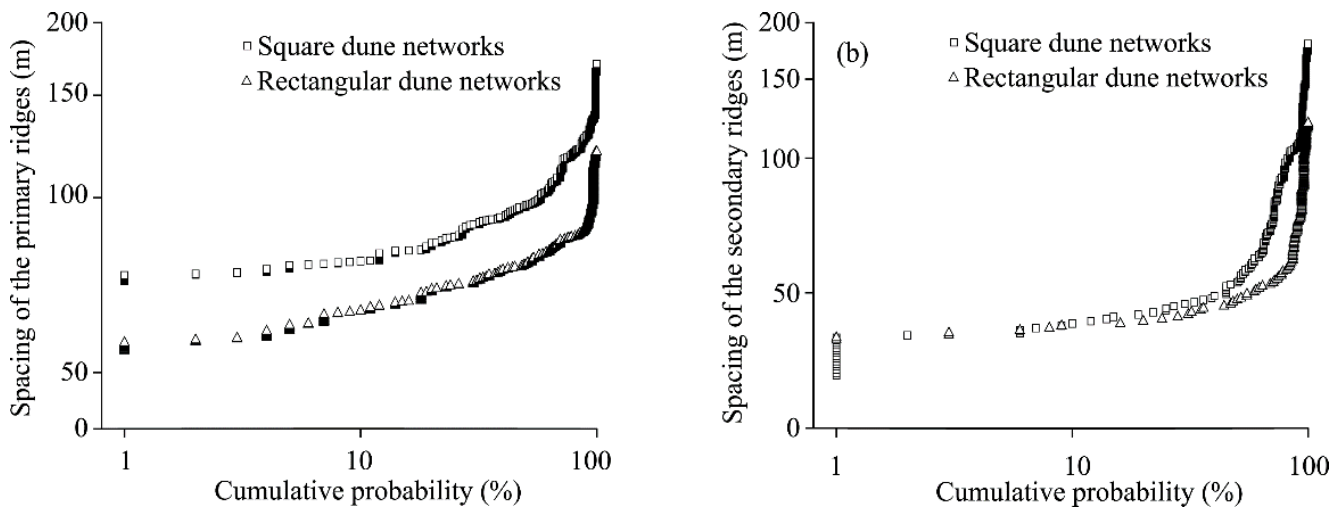

Fig. 5 Cumulative probability distributions of ridge spacings for primary dune ridges (a) and secondary dune ridges (b)

Geomorphological patterns of the dune networks in the present study show regional variation. In essence, the combination of factors that influence the origin and evolution of aeolian 
geomorphology includes the wind regime and sand supply that vary spatially in the study region, leading to differences in the morphology of the dunes. Wind regime and sand supply (which is determined by the characteristics of the sand source) are the major factors that determine the morphology of dune networks. In the western Tengger Desert, the potential sand transport is greater than that in the southeast, with the annual drift potential (DP) decreasing from 139 vector units (VU) to $69 \mathrm{VU}$ in this direction (Fig. 6). Therefore, the spacing between the primary ridges of the square dune networks is significantly greater than that of the rectangular dune networks. Wind regime controls the overall spatial variation in ridge length. From the northwest to the southeast of the desert, the wind direction becomes more complicated. The length of the primary ridges of the rectangular dune networks is greater than that of the square dune networks.

Figure 6 shows that west and northwest winds are the dominant winds in the square dune network region. Northwest and southeast winds are dominant in the rectangular dune network region. The wind regime and sand supply in the research area change gradually from northwest to southeast. The dominant direction of sand-driving winds (i.e. the resultant drift direction (RDD)) remains unchanged, but the secondary wind direction differs among sites. In the northwestern desert (site B), the wind direction changes from northwest in spring and summer to southeast in autumn. In the southeastern desert (site A), the wind direction changes from northwest in spring and east in summer to south in autumn.

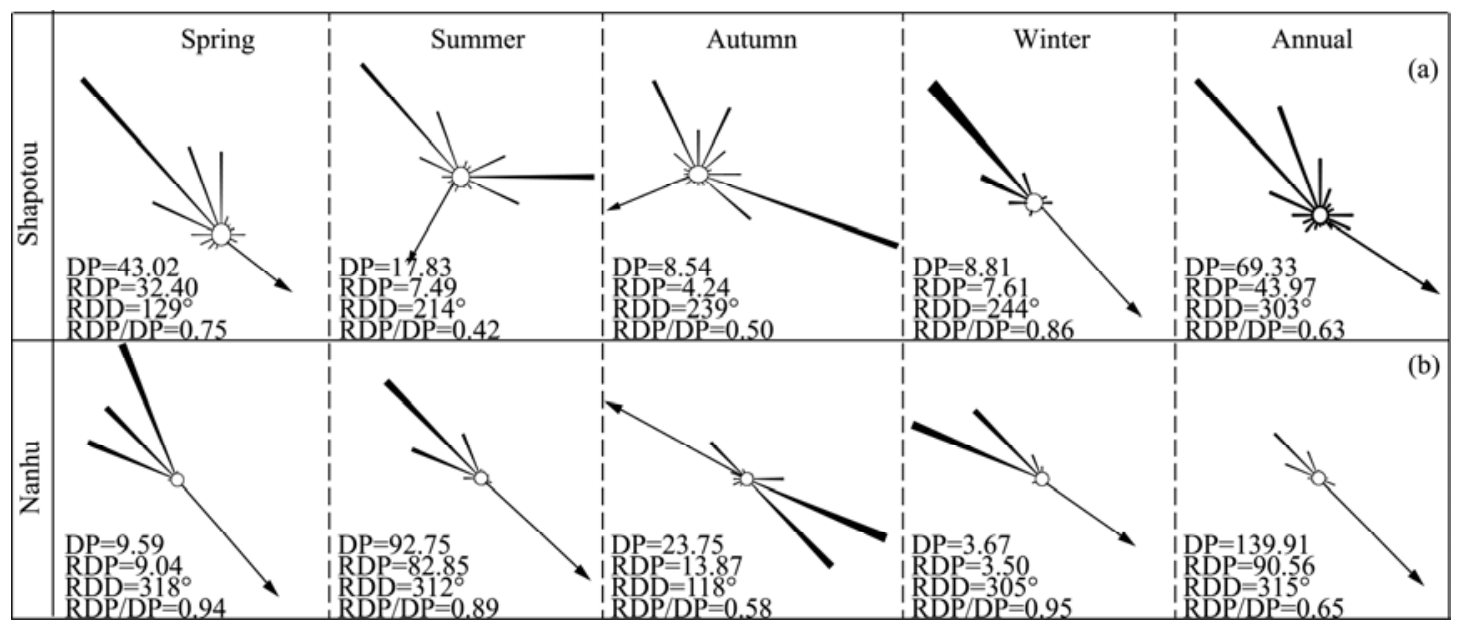

Fig. 6 Wind regimes of the two reticulate dune areas: Shapotou at the southeast desert (a) and Nanhu at the northwest desert (b). DP, the drift potential in vector units; RDP, the resultant drift potential; RDD (arrows), the resultant drift direction; RDP/DP, the directional variability index.

\subsection{Ridge orientation and defect density}

Ewing et al. (2006) pointed out that orientation of dune ridge within a dune field became increasingly consistent as dunes evolve. Table 1 shows that the strike of the dunes ranges from $37^{\circ}$ and $70^{\circ}$, and does not show a consistent trend from the northwest to the southeast. Due to the spatial differences in the wind regime, the spatial variation in the distribution of dune strikes shows no obvious correspondence with the length of the ridges and their spacing, suggesting that the factors controlling dune development are complicated.

The range of the orientation generally increases and the wind regime becomes increasingly complex from northwest to southeast (i.e. from the rectangular dune networks at site $B$ to the square dune networks at site A; Fig. 6). Figure 7 shows the rose diagram of the orientation of the two types of dune networks. The range of orientations of rectangular dune networks becomes narrower than that of the square dune networks, which reflects the complexity of wind directions. This is consistent with results from the length of primary ridges of the dune networks.

Defect density is a relatively independent dynamical variable among the parameters that are related to the geomorphologic patterns of dunes (Ewing et al., 2006). The defect density of square 
and rectangular dune networks is 9.3 and 7.8, respectively. Figure 8 shows the relationship between the defect density and the length of primary ridges of the two types of dune networks. The spatial variation of defect density corresponds weakly to the ridge length (i.e. the longer the length, the smaller the defect density). However, defect density is irrelevant to spacing (Fig. 9), which reflects the complexity of factors concerning the origin and evolution of dunes and the asynchronism between defect density and spacing.
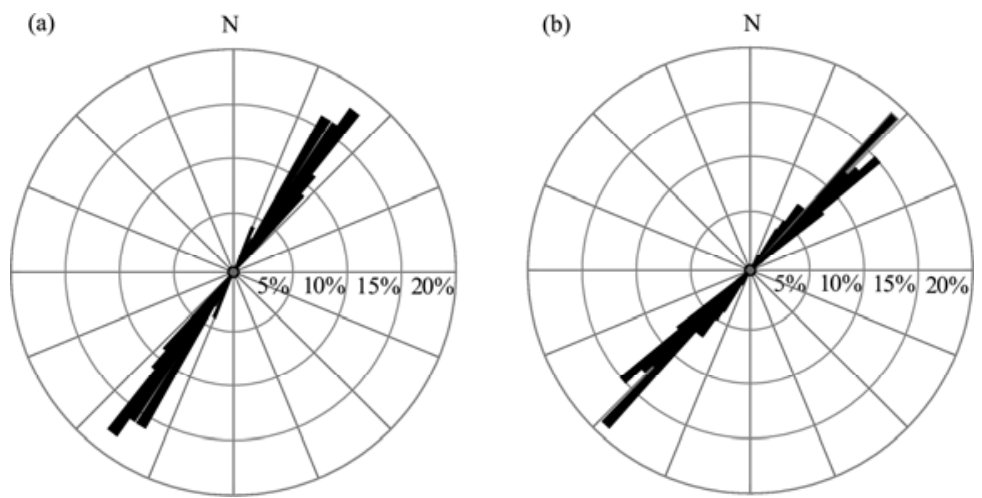

Fig. 7 Rose diagram of the orientation of the primary ridges of the square dune networks (a) and the rectangular dune networks (b)
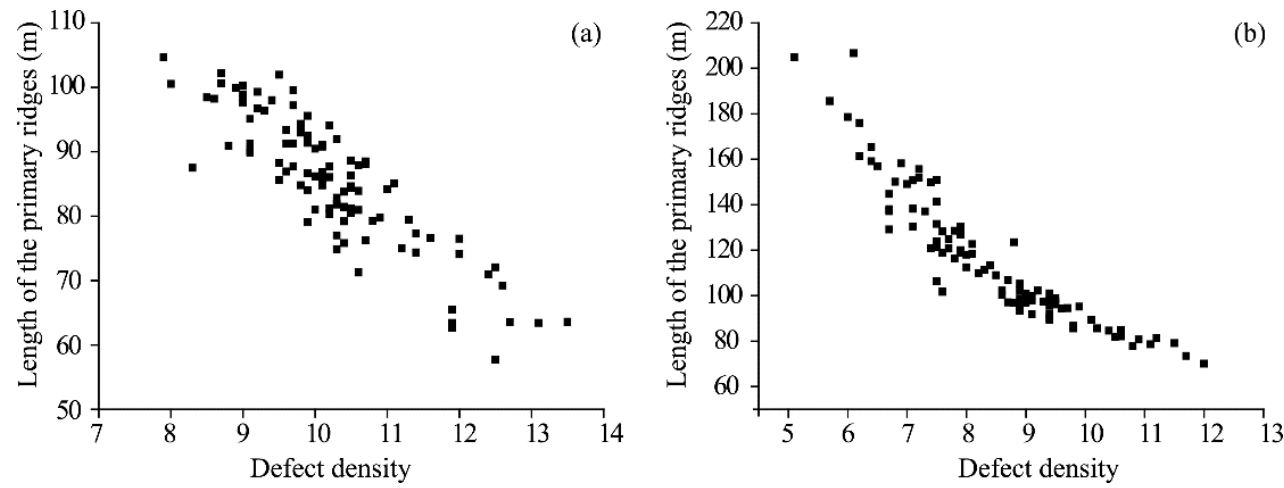

Fig. 8 The relationship between the defect density and the length of primary ridges for the square dune networks (a) and the rectangular dune networks (b)
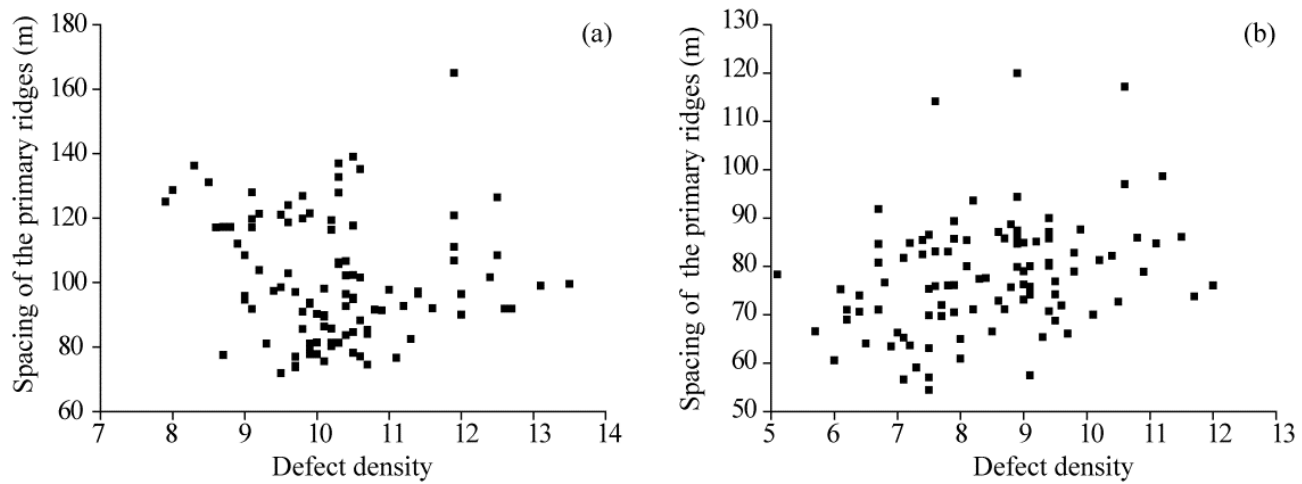

Fig. 9 The relationship between the defect density and the spacing for the square dune networks (a) and the rectangular dune networks (b)

\subsection{Construction time of dune networks}

According to the theory of self-organization in complex systems, specific geomorphologic 
patterns form during specific development stages (Werner, 1999). On that basis, the geomorphologic pattern in a dune field is largely a function of time that has elapsed since formation of the dunes. Werner and Kocurek (1999) noted in their model of defect dynamics that the connection and disappearance of defects caused the ridge spacing to increase as a function of the logarithm of time, and established a function to describe this relationship. Ewing et al. (2006) studied the parameters related to the geomorphologic patterns of dunes in several deserts in southern Africa and North America and found a correlation between the age of a dune and its ridge spacing, and defect density (Fig. 10). This can be compared with the calculation results of Werner and Kocurek's model. Both models could be used to estimate the formation time of dunes in different sizes. Ewing et al. (2006) successfully used this approach in the Namib Desert of Africa and determined that the age of linear dunes in the Namib was 16-27 ka. Based on these relationships, both research groups were able to estimate the construction time of dunes with a range of sizes in Africa's Namib Desert. We attempt to estimate the construction time of dune networks in the Tengger Desert in light of the successful experiences of Werner and Kocurek (1999) and Ewing et al. (2006). Figure 10 shows the construction time of dune networks based on dune spacing and defect density. We use the fitting curve of Ewing et al. (2006) to estimate the construction time of dune networks in the Tengger Desert based on spacing and defect density. The estimated construction time based on spacing is $1.75 \mathrm{ka} \mathrm{BP}$ for square dune networks and 1.05 ka BP for rectangular dune networks, while that estimated based on defect density is 1.06 and 1.05 ka BP for square dune networks and rectangular dune networks, respectively. The average of these dates is $1.27 \mathrm{ka} \mathrm{BP}$. It can be roughly taken that the formation of the dune networks in our study area began at about $1.3 \mathrm{ka} \mathrm{BP}$ when the climate became dry and cold and sand material from palaeolake formed dune networks. This estimated construction time seems reasonable. Formation of dune networks or other dunes in the Tengger Desert must have been later than the formation of the desert. Zhang et al. (2004) indicated that the Tengger Desert was a palaeolake before $22 \mathrm{ka} \mathrm{BP}$, which disappeared because of climate change. The evolution of modern Tengger Desert has experienced several expansion and shrink stages (Qiang et al, 2000). It must be emphasized that the above estimated formation time can only represent a tentative idea about the construction time of the dune networks in the Tengger Desert.
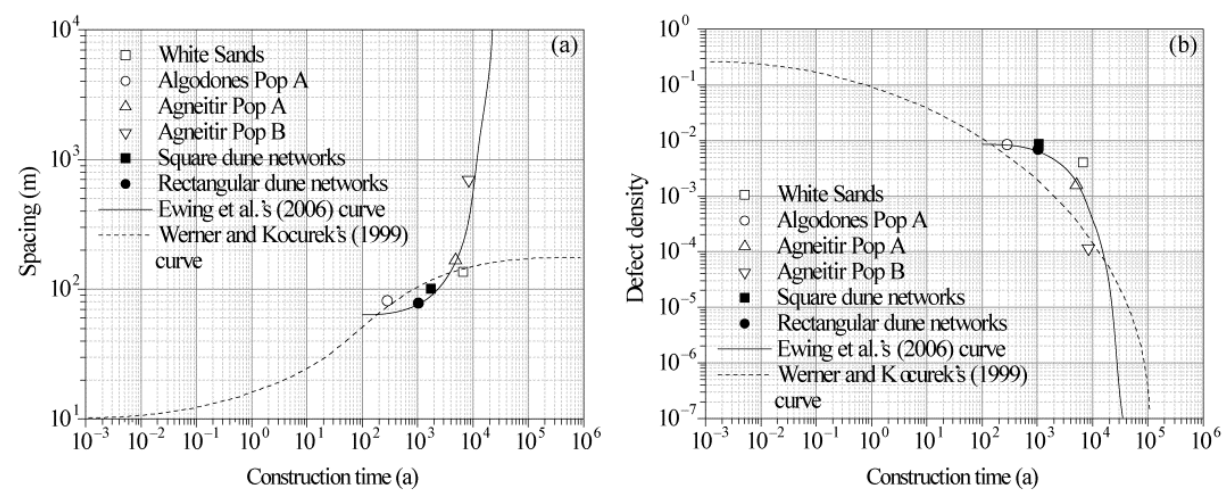

Fig. 10 Construction time of dune networks against spacing (a) and defect density (b)

\section{Conclusions}

In this paper, we use the MATLAB software to identify and extract the positions of dune ridges, thereby providing a fast and reliable method to measure and calculate several pattern parameters of dune networks in the Tengger Desert. The length of the primary ridges of the rectangular dune networks is greater than that of the square dune networks. The spacing of the main ridge of the square dune networks is greater than that of the rectangular dune networks. The spatial variation in defect density corresponds strongly to the length of dune ridges, with longer ridges having a smaller defect density. Spacing and defect density may be helpful parameters to estimate the 
construction time of dunes, a tentative estimate of $1.3 \mathrm{ka} \mathrm{BP}$ is proposed for the formation time of the dune networks in the Tengger Desert, whose reliability is to be evaluated by dating results. The wind regime and source characteristics appear to be the major factors that determine the morphology of the dune networks in our study area. In the western Tengger Desert, the wind power is greater than in the southeast, so the length of the main ridges of the rectangular dune networks is greater than that of the square dune networks. The wind regime also controls the overall spatial pattern of the spacing of the primary ridges. The wind power in the desert decreases from the northwest to the southeast, but the wind roses become increasingly complex.

\section{Acknowledgments}

We gratefully acknowledge funding from the Ministry of Science and Technology of the People's Republic of China (2013CB956000) and the National Natural Science Foundation of China (41130533).

\section{References}

Breed C S, Fryberger S C, Andrews S, et al. 2004. Regional studies of sand seas using LANDSAT (ERTS) imagery. In: McKee E D. A Study of Global Sand Seas. Honolulu: University Press of the Pacific, 305-397.

Brookfield M E. 1970. Dune trends and wind regime in central Australia. Zeitschrift für Geomorphologie, Supplement Band, 10: 121-158.

Bullard J E. 1997. Vegetation and dryland geomorphology. In: Thomas D S G. Arid Zone Geomorphology: Process, Form and Change in Dryland. $2^{\text {nd }}$ ed. Chichester: John Wiley \& Sons, Ltd., 109-131.

Chen W R, Chen X Z. 1965. Water Condition of Dune Network in the Southeastern Tengger Desert. Desert Control Research, No. 7. Beijing: Science Press, 120-126. (in Chinese)

Cooke R U, Warren A. 1973. Geomorphology in Deserts. London: Batsford, 288-306.

Cooke R U, Warren A, Goudie A S. 1993. Desert Geomorphology. London: UCL Press, 393-394.

Ewing R C, Kocurek G, Lake L W. 2006. Pattern analysis of dune-field parameters. Earth Surface Processes and Landforms, 31(9): 1176-1191.

Hasi E, Dong G R, Wang G Y. 1999. Morphodynamic study of reticulate dunes at Southeastern fringe of the Tengger Desert. Science in China Series D: Earth Sciences, 42(2): 207-215.

Hallet B. 1990. Spatial self-organization in geomorphology: from periodic bedforms and patterned ground to scale-invariant topography. Earth-Science Reviews, 29(1-4): 57-75.

Hasi E. 1995. Characteristics and controlling factors of dune morphometry in the southeastern fringe of Tengger desert. Journal of Desert Research, 15(2): 136-142. (in Chinese)

Hasi E, Wang G Y. 1996. Grain-size variation on transeverse dune in connection with slope morphology at southeastern fringe of Tengger Desert. Journal of Desert Research, 16(3): 216-221. (in Chinese)

Hasi E. 1998. Grain-size characteritics and mechanism of network dune in the southeastern Tengger Desert. Geographical Research, 17(2): 178-184. (in Chinese)

Illenberger W K. 1988. The dunes of the Alexandria coastal dunefield, Algoa bay, South Africa. South African Journal of Geology, 91(3): 381-390.

Jiang C W, Dong Z B, Wen Q. 2013. Extraction of dune crest lines and calculation of dune-field pattern parameters on remote sensing image based on MATLAB platform. Journal of Desert Research, 33(6): 1636-1642. (in Chinese)

Lancaster N. 1989. The Namib Sand Sea: Dune Forms, Processes and Sediments. Rotterdam: Balkema, 152-167.

Ling Y Q, Jin J, Zhen J G. 1988. Movemental law of blown sand in Shapotou Area. In: Research on Fluid Sand at Shapotou Area at the Southeastern Edge of Tengger Desert (Vol. 2). Yinchuan: Ningxia People's Publishing House, 309-317. (in Chinese)

Liu X W. 1995. Experimental Wind-Sand Flow Physics and Sand Drift Control Engineering. Beijing: Science Press, 114-115. (in Chinese)

Livingstone I, Warren A. 1996. Aeolian Geomorphology: An Introduction. London: Addison Wesley Longman Limited, 211.

Mabbutt J A. 1977. Desert landforms. Canberra: Australian National University Press, 243-244.

Pye K, Tsoar H. 1990. Eolian Sand and Sand Dunes. London: Unwin Hyman, 204.

Qiang M R, Li S, Jing M, et al. 2000. Aeolian deposits on the southeastern margin of Tengger desert and desert evolution during the last 60,000 years. Journal of Desert Research, 20(3): 256-259. (in Chinese)

Warren A, Kay S. 1987. Dune networks. In: Frostick L E, Reid I. Desert Sediment: Ancient and Modern. London: Geological 
Society Special Publication, 205-212.

Warren A. 1988. The dunes of the Wahiba Sands. In: Dutton R W. Scientific Results of the Royal Geographical Society's Oman Wahiba Sands Project 1985-1987, Journal of Oman Studies. Special Report 3. Muscat, Oman, 131-160.

Wasson R J, Hyde R. 1983a. A test of granulometric control of desert dune geometry. Earth Surface Processes and Landforms, 8(4): 301-312.

Wasson R J, Hyde R. 1983b. Factors determining desert dune type. Nature, 304(5924): 337-339.

Werner B T. 1999. Complexity in natural landform patterns. Science, 284(5411): 102-104.

Werner B T, Kocurek G. 1999. Bedform spacing from defect dynamics. Geology, 27(8): 727-730.

Wilson I G. 1972. Aeolian bedforms-their development and origins. Sedimentology, 19(3-4): 173-210.

Wu Z. 1987. Aeolian Sand Geomorphology. Beijing: Science Press, 87-153. (in Chinese)

Yang G S, Huang Z H, Di X M. 1994. The Charateristics of Natural Environment and Sand Stablization by Air Seedlings at the Southeast Edge of Tengger Desert in China. Beijing: Science Press, 12-13. (in Chinese)

Zhang H C, Peng J L, Ma Y Z, et al. 2004. Late quaternary palaeolake levels in Tengger Desert, NW China. Palaeogeography, Palaeoclimatology, Palaeoecology, 211(1-2): 45-58.

Zhang Z C, Dong Z B, Wen Q, et al. 2015a. Wind regimes and Aeolian geomorphology in the western and southwestern Tengger Desert, NW China. Geological Journal, 50(6): 707-719.

Zhang Z C, Dong Z B, Li J Y. 2015b. Grain-size characteristics of dune networks in China's Tengger Desert. Geografiska Annaler: Series A, Physical Geography, 97(4): 681-693.

Zhong D C. 1999. The dynamic changes and trends of modern desert in China. Advances in Earth Sciences, 14(3): 229-234. (in Chinese)

Zhu Z D, Wu Z, Di X, et al. 1980. Introduction of Deserts in China. Beijing: Science Press, 107. (in Chinese) 